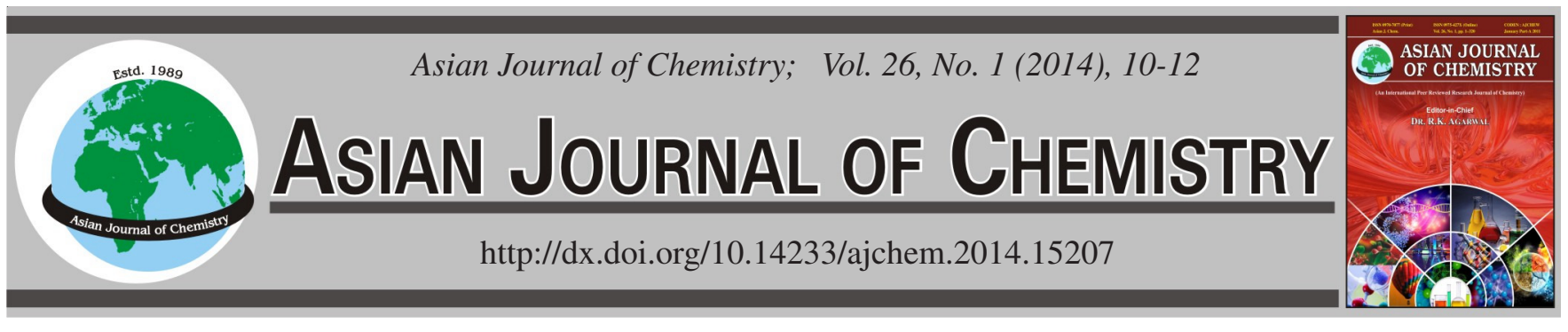

\title{
Modification of Polypeptide-graft-poly(ethylene glycol) Film by Blending with Poly(butyl acrylate-co-methyl methacrylate)
}

\author{
Guo-Quan Zhu, Fa-Gang Wang ${ }^{*}$, Ke-Jing Xu, Qiao-Chun Gao and Yu-Ying Liu
}

School of Materials Science and Engineering, Shandong University of Technology, Zibo 255049, P.R. China

*Corresponding author: E-mail: fagangwang@126.com

Received: 25 January 2013;

Accepted: 16 July 2013;

Published online: 26 December 2013;

AJC-14461

\begin{abstract}
A series of poly $(\gamma$-benzyl $L$-glutamate)-graft-poly(ethylene glycol)/poly(butyl acrylate-co-methyl methacrylate) (PBLG-graft-PEG/P(BAco-MMA)) blend films were prepared by the solution casting method. Surface morphologies of the polymer blend films were investigated by scanning electron microscopy. Mechanical and chemical properties of the polymer blend films were studied using tensile tests and contact angle tests. It was revealed that the introduction of $\mathrm{P}(\mathrm{BA}-\mathrm{co}-\mathrm{MMA})$ into polypeptide graft copolymer could exert marked effects on the surface morphology and the properties of the polypeptide graft copolymer film.
\end{abstract}

Keywords: Polypeptide graft copolymer, Blend film, Morphology, Properties.

\section{INTRODUCTION}

It is well-known that the polypeptides and their copolymers have attracted much interest for their potential applications based on their excellent biodegradable and biocompatible properties $^{1-8}$. The synthesized polypeptides and their copolymers have been studied widely in the fields of functional biomaterials, protein simulation, polymer carriers for protein, macromolecular conformational research, catalysis, nanoreactors and drug delivery systems. etc $^{9-13}$. For polypeptide copolymer films, an important application is for temporary artificial skin substrates in burn therapy ${ }^{14,15}$.

Compared with pure polypeptides or their copolymers, relatively hard polypeptide copolymer/flexible polymer blend films have received little attention. To the best of our knowledge, no experimental work has so far been reported on the surface morphology and the properties of PBLG-graft-PEG/ $\mathrm{P}(\mathrm{BA}-\mathrm{co}-\mathrm{MMA})$ blend film. As known, polypeptide is a rigid polymer, while $\mathrm{P}$ (BA-co-MMA) (wt ratio of BA to MMA: $3: 1)$ is a flexible polymer ${ }^{16,17}$, the introduction of $\mathrm{P}\left(\mathrm{BA}-\right.$ co- $^{-}$ MMA) chains could affect the properties of the polypeptide copolymer films and further enlarge the research field of the polypeptide copolymers. In the present work, PBLG-graftPEG/P(BA-co-MMA) blend film was prepared by casting the polymer blend solution in dichloroethane. Surface morphologies of the polymer blend films were investigated by scanning electron microscopy technique. Mechanical and chemical properties of the polymer blend films were studied using tensile tests and contact angle tests. It was found that the introduction of $\mathrm{P}$ (BA-co-MMA) into polypeptide graft copolymer could exert marked effects on the surface morphology and the properties of the polypeptide graft copolymer film.

EXPERIMENTAL

Poly(butyl acrylate-co-methyl methacrylate $)\left(\mathrm{M}_{\mathrm{w}}=40000\right.$, wt ratio of BA to MMA: 3:1) was purchased from Shandong Shituo Chemical Co. Ltd. (China). Poly(ethylene glycol) monomethylether (mPEG, $\mathrm{M}_{\mathrm{w}}=750$ ) was purchased from Sigma Inc. (USA) and used without further purification. Hexane, tetrahydrofuran (THF) and 1,4-dioxane are of analytical grade and dried with sodium to remove water before use. Dichloroethane and other solvents are of analytical grade and used without further purification.

Synthesis of PBLG and PBLG-graft-PEG: The PBLG sample was prepared by a standard $N$-carboxyl- $\gamma$-benzyl- $L$ glutamate anhydride (NCA) method ${ }^{1-3}$. Molecular weight of PBLG was estimated from the intrinsic viscosity measured in dichloroacetic acid (DCA) ${ }^{18}$. PBLG- graft-PEG copolymer was obtained by the ester exchange reaction of the PBLG homopolymer with mPEG $\left(\mathrm{M}_{\mathrm{w}}=750\right)$ in 1,2-dichloroethane with $p$-toluenesulfonic acid as a catalyst according to the described method $^{1,2}$. The molecular weight of the PBLG used in the ester exchange reaction was about 80000 . The grafting percentage of PBLG-graft-PEG was $9.5 \%$ calculated according to the document $^{2,3}$.

Preparation of PBLG-graft-PEG/P(BA-co-MMA) blend film: The polymer blend films were prepared by casting a $30 \mathrm{wt} \%$ polymer blend solution in dichloroethane onto clean 
glass plates and drying them under vacuum at $50{ }^{\circ} \mathrm{C}$. Also, it is found that, when $\mathrm{P}(\mathrm{BA}-\mathrm{co}$-MMA) mole content in polymer blend is over $12 \%$, the polymer blend can not form continuous film.

Test method: Scanning electron microscopy investigation was carried out using a scanning electron microscope (Sirin 200, FEI, Holland). Gold was sprayed on the polymer blend films in vacuum. Acceleration voltage was $10 \mathrm{kV}$. Tensile tests were carried out with an Instron Model 4468 universal testing machine (Digital Instruments, USA). The crosshead speed was set to $100 \mathrm{~mm} / \mathrm{min}$. For each data point, five samples were tested and the average value was taken. A $5 \mu \mathrm{L}$ drop of pure distilled water was placed on the polymer blend film surface using a syringe with a 22-gauge needle. The static contact angle was measured with an optical contact angle meter CAM 200 (KSV Instrument Ltd., Finland). The measurements of each contact angle were performed within $10 \mathrm{~s}$ after each drop to ensure that the droplet did not soak into the compact. The surface contact angles were the mean of five determinations ${ }^{19}$. Water-resistant pressure $(\mathrm{mm})$ measurements of the polymer blend films were carried out according to a conventional method. The round sample films were used to seal the mouth of a long round tube with graduation in millimeters (tube diameter: $10 \mathrm{~mm}$ ). After the tube mouth was sealed with the polymer blend film, it was upset and deionized water was added into the long round tube drop by drop. As soon as the deionized water permeated through the polymer blend film, the height of water column was written down ${ }^{20}$.

\section{RESULTS AND DISCUSSION}

The surface morphologies of PBLG- raft-PEG/P(BA-coMMA) blend films with various $\mathrm{P}(\mathrm{BA}-\mathrm{co}-\mathrm{MMA})$ mole contents were studied by scanning electron microscopy. Fig. 1 presents the surface morphologies of the polymer blend films with various $\mathrm{P}$ (BA-co-MMA) mole contents: (a), 0 and (b) $6 \%$. As it can be seen from Fig. 1, the surface morphologies of the polymer blend films are various with increasing $\mathrm{P}(\mathrm{BA}-\mathrm{co}-$ MMA) mole contents. With the increase of $\mathrm{P}(\mathrm{BA}-\mathrm{co}-\mathrm{MMA})$ mole contents, the surface morphologies of the polymer blend films become more coarse and the surface density increases, which is caused by the interaction between the polypeptide copolymer chains and the P(BA-co-MMA) segments through entanglement. This phenomenon indicates that the difference of the surface morphologies between the polypeptide graft copolymer film and the polymer blend film could be attributed to the introduction of $\mathrm{P}(\mathrm{BA}-\mathrm{co}-\mathrm{MMA})$ segments.

Tensile tests: Fig. 2 shows the relationship between the tensile strength of the polymer blend film and the P(BA-coMMA) mole contents. As seen from Fig. 2, the tensile strength of the polymer blend film decreased with the increase of the $\mathrm{P}(\mathrm{BA}-\mathrm{co}-\mathrm{MMA})$ mole contents in the polymer blend. As mentioned above, compared with the polypeptide graft copolymer, $\mathrm{P}(\mathrm{BA}-\mathrm{co}-\mathrm{MMA}$ ) (wt ratio of BA to MMA: 3:1) is relatively flexible polymer, suggesting the decrease of the tensile strength of polymer blend film is related with the introduction of the flexible $\mathrm{P}(\mathrm{BA}-\mathrm{co}$-MMA) segments. Under permitted $\mathrm{P}(\mathrm{BA}-\mathrm{co}-$ MMA) mole content, the higher the $\mathrm{P}(\mathrm{BA}-\mathrm{co}$-MMA) mole content, the lower the tensile strength of the polymer blend film.
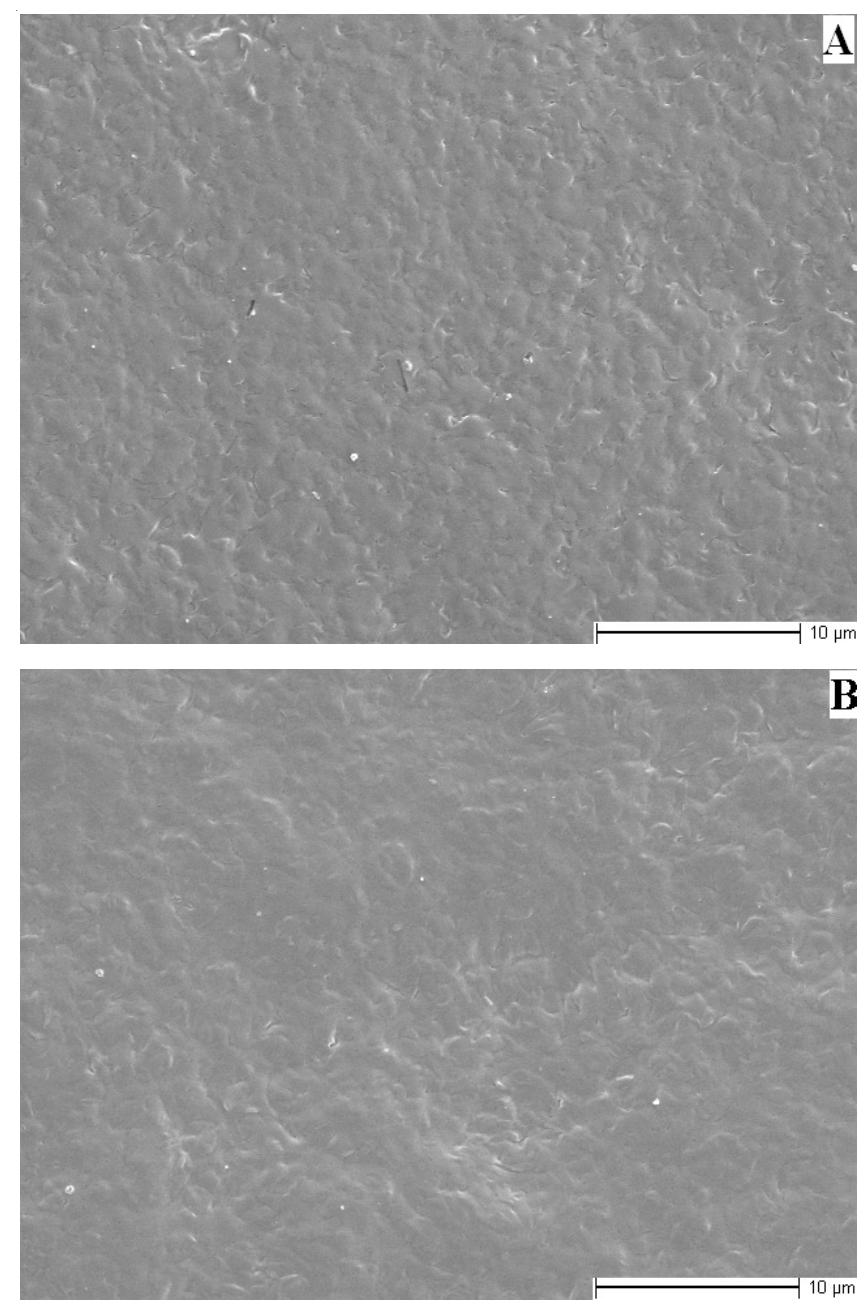

Fig. 1. SEM photographs of the polymer blend films with various P(BAco-MMA) mole contents: (a), 0 and (b) $6 \%$

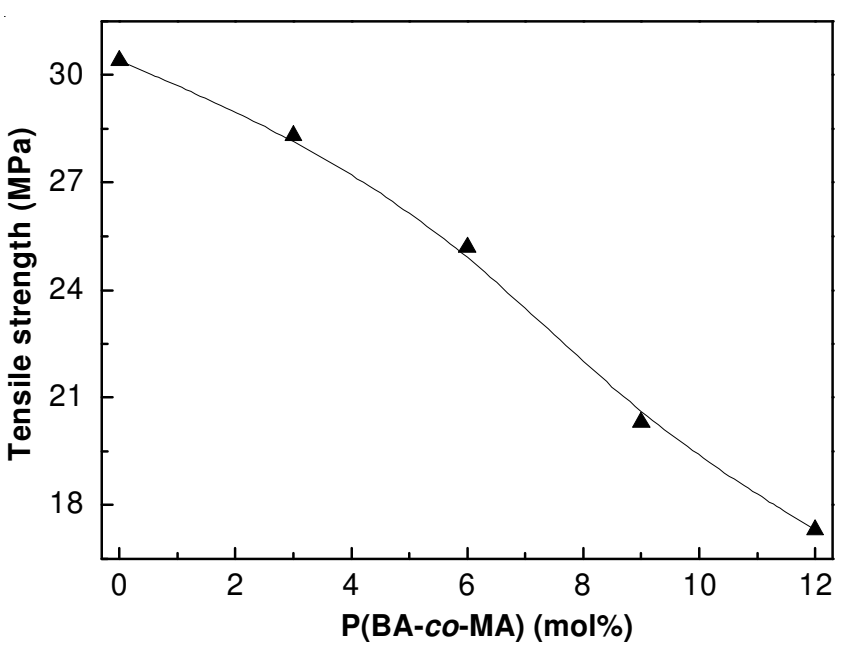

Fig. 2. Relationship between the tensile strength of the polymer blend film and the $\mathrm{P}(\mathrm{BA}-$-co-MMA) mole contents

Surface contact angle tests: Fig. 3 indicates the relationship between the surface contact angle of the polymer blend film and the $\mathrm{P}(\mathrm{BA}-$ co-MMA) mole contents. As is shown in Fig. 3, the surface contact angle of the polymer blend film increased with increasing the $\mathrm{P}(\mathrm{BA}-\mathrm{co}-\mathrm{MMA})$ mole contents in the polymer blend, indicating that the hydrophobicity of 


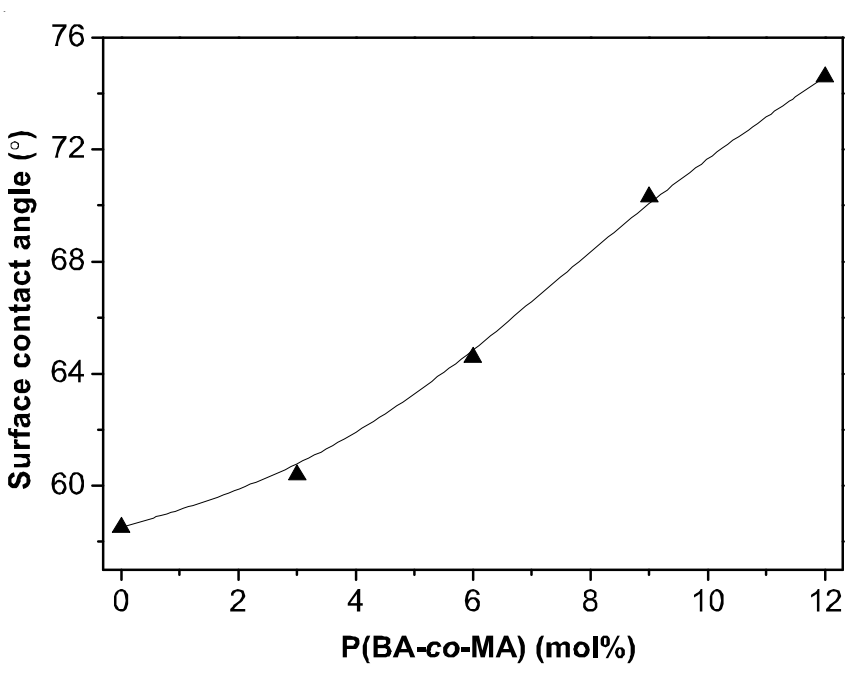

Fig. 3. Relationship between the surface contact angle of the polymer blend film and the P(BA-co-MMA) mole contents

the polymer blend film increased. As known, the PEG segments in the polypeptide graft copolymer hold hydrophilicity, it means that the polypeptide graft copolymer film holds a little hydrophilicity; while $\mathrm{P}(\mathrm{BA}-\mathrm{co}-\mathrm{MMA})$ chains are hydrophobic, indicating that the introduction of $\mathrm{P}(\mathrm{BA}-\mathrm{co}-\mathrm{MMA})$ chains increased the hydrophobicity the polymer blend film.

Water-resistant pressure (mm) tests: Fig. 4 presents the relationship between the water-resistant pressure of the polymer blend film and the P(BA-co-MMA) mole contents. As shown in Fig. 4, the water-resistance pressure of the polymer blend film increased with the increase of the P(BA-co-MMA) mole contents in the polymer blend, suggesting that the hydrophobicity of the polymer blend film increased. As discussed above, the polypeptide graft copolymer holds a little hydrophilicity and the P(BA-co-MMA) segments are hydrophobic, suggesting that the increase of the water-resistant pressure of the polymer blend film was concerned with the introduction of the hydrophobic P(BA-co-MMA) segments.

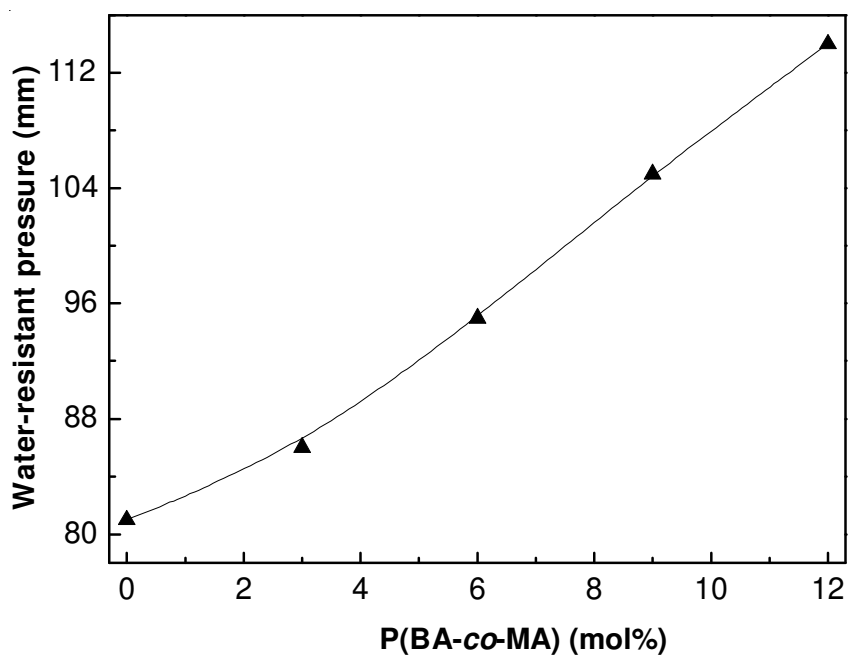

Fig. 4. Relationship between the water-resistant pressure of the polymer blend film and the P(BA-co-MMA) mole contents

\section{Conclusion}

A series of PBLG-graft-PEG/P(BA-co-MMA) blend films were prepared by casting the polymer blend solution in dichloroethane. Surface morphologies of the polymer blend films were investigated by scanning electron microscopy. Mechanical and chemical properties of the polymer blend films were studied using tensile tests and contact angle tests. Scanning electron microscopy photographs attested that the introduction of $\mathrm{P}$ (BA-co-MMA) changed the surface morphologies of the polymer blend films. Tensile tests verified that the introduction of $\mathrm{P}(\mathrm{BA}-\mathrm{co}-\mathrm{MMA})$ decreased the tensile strength of the polymer blend film. Both the surface contact angle tests and the water-resistant pressure tests proved that the introduction of the $\mathrm{P}(\mathrm{BA}-\mathrm{co}$-MMA) chains increased the hydrophobicity of the polymer blend films.

\section{ACKNOWLEDGEMENTS}

This work is supported by the Natural Science Foundation of Shandong Province (No. ZR2011EMM009).

\section{REFERENCES}

1. T. Li, J.P. Lin, T. Chen and S.N. Zhang, Polymer, 47, 4485 (2006).

2. J.P. Lin, G.Q. Zhu, X.M. Zhu, S.L. Lin, T. Nose and W.W. Ding, Polymer, 49, 1132 (2008).

3. D.M. Tang, J.P. Lin, S.L. Lin, S.N. Zhang, T. Chen and X.H. Tian, Macromol. Rapid Commun., 25, 1241 (2004).

4. C.S. Cho, J.B. Cheon, Y.I. Jeong, I.S. Kim, S.H. Kim and T. Akaike, Macromol. Rapid Commun., 18, 361 (1997).

5. C.S. Cho, J.W. Nah, Y.I. Jeong, J.B. Cheon, S. Asayama, H. Ise and T. Akaike, Polymer, 40, 6769 (1999).

6. G.Q. Zhu, Chem. Pap., 63, 683 (2009).

7. G.Q. Zhu, Chem. Pap., 64, 34 (2010).

8. G.Q. Zhu, Fibers Polym., 10, 425 (2009).

9. X.F. Zhong, S.K. Varshney and A. Eisenberg, Macromolecules, 25, 7160 (1992).

10. M. Moffitt and A. Eisenberg, Macromolecules, 30, 4363 (1997).

11. Z.S. Gao, A. Desjardins and A. Eisenberg, Macromolecules, 25, 1300 (1992).

12. A. Kitahara, Adv. Colloid Interf. Sci., 12, 109 (1980).

13. A. Rolland, J. O'Mullane, J. Goddard, L. Brookman and K. Petrak, J. Appl. Polym. Sci., 44, 1195 (1992).

14. K. Jokei, M. Oka, T. Hayashi and Y. Miyachi, Eur. Polym. J., 35, 945 (1999).

15. Y. Miyachi, K. Jokei, M. Oka and T. Hayashi, Eur. Polym. J., 35, 767 (1999).

16. R. Singhal and I.A. Gupta, Int. J. Polym. Mater., 59, 757 (2010).

17. G.Q. Zhu, G.C. Li and P. Wang, Polym.-Plast. Technol. Eng., 50, 1470 (2011).

18. A. Abe and T. Yamazaki, Macromolecules, 22, 2138 (1989).

19. L.Q. Bai, L.J. Zhu, S.J. Min, L. Liu, Y.R. Cai and J.M. Yao, Appl. Surf. Sci., 254, 2988 (2008).

20. G.Q. Zhu, Fibers Polym., 8, 243 (2007). 